\title{
The Strategy and Practice on Promoting the Application of Higher Vocational Teaching Resources Database under Big Data Environment
}

\author{
Li Liangtian
}

School of Mechanical and Electrical Engineering, Shenzhen Polytechnic, Shenzhen,518055,China 1.The Ministry of Education's project of the junior vocational education teaching resource library of

numerical control equipment and maintenance specialty(2012-2-4);

2.The Guangdong Provincial Education Department's project of quality curriculum of the junior voc ational education teaching resource library of numerical control equipment and maintenance speci alty (201401221);

Keyword: Teaching resources database; School - Enterprise cooperation; Big data; Micro Class Abstract: After five years development, national teaching resources database has formed certain scale. However, the massive application of teaching resources database is still facing problems, for example, small range application and low utilization, weak practical effect about sharing by college and enterprise, which leads to a certain degree of resources waste. The reason why the application effect of teaching resources database is not good enough is deeply analyzed in the paper based on teaching resources database practice. The solution of school-enterprise cooperation is studied. A refreshing three party structure model of student, teacher and enterprise is proposed, and specific improvement scheme and suggestion for practice have been put forward to give reference for later resources database construction.

\section{INTRODUCTION}

In order to deepen higher vocational education teaching reform, and promote high quality teaching resources sharing, the Ministry of Education launched higher vocational education professional teaching resource database construction in 2010. By 2015, our country has launched a total of 78 vocational colleges teaching resource database projects in six professional groups, and most projects constructed before 2014 have been in use. The aim of construction project is to service teachers teaching, students and society autonomous learning by widely used sharing resource database, and ultimately drives the related field's professional development teaching resources, promotes professional teaching reform, and improve the quality of professional personnel training and social service ability of higher vocational education profession [1]. Through the analysis of the database projects constructed, they have covered national industrial planning and professions closely linked to social and economic development with a large quantity of points, and have constructed the desired size. But, on the application, the database remains small application range, low utilization rate, and low effectiveness. Database applications have great gap to the expected goal, and they are not in conformity with construction purpose. Domestic scholars in recent years, such as Zhou Danong, Li Liping, Dai Yong, and Guan Ping put forward the existing problems and suggestion by studying teaching resource database and focus on design and architecture of the database $[2,3,4,5]$, and there are very little literature about the use of the completed database and the application research. This article mainly explores the deep reasons from the application status quo of the database, analyzes the reasons of the inefficient existing database application effect, and puts forward proposals and provides reference for subsequent database construction.

\section{ANALYSIS OF THE APPLICATION STATUS QUO OF THE DATABASE}

A. The effectiveness of resource application promotion is not strong, and resource utilization is low The author analyzes the established 42 countries teaching database sites, and finds that various number of registered users has basically reached more than 20000 size, but the vast majority of average daily visits the site is less than 200, and downloads resources distribution is uneven, most resources type is documents and PPT, and video downloads are at least. It may mainly be influenced by the factors of slow download speeds. And, this kind of condition has no substantial improvement both in early built database, or newly built database. The above situation shows that the current common database construction problems include heavy construction, light application, heavy show 
report, and light effect and so on. It is visible that the database design is not application oriented, cares nothing in use. As a product, consider only design and not consumer and the market, which is likely to lead to waste of resources.

\section{$B$. There are deviations in the actual situation of platform construction and positioning}

Resource database platform construction goal is to build a "learning center" to provide service in many class objects, and the actual construction situation is that most professional teaching resource databases are constructed into simple library professional courses databases. Simply built course database with core courses of this major separately, and stack them into a platform to build up professional teaching resources database. Curriculum are completely independent, and because each course builders are mostly from different colleges and universities, they build up their respective responsible course, resulting in some overlapping knowledge content of the construction, or those cannot be used by each other. A professional teaching database is a simple sum of teaching resource, rather than a distinct, unified and orderly organic whole, and curriculum are lack of links.

C. There are problems in university-enterprise sharing mechanism and enterprise investment enthusiasm remains to be improved

Database platform does not become staff training application platform for those involved in building enterprise, the amount of other insurance enterprise employee is rarer in application database. Enterprises are not using the database either because they cannot or are not convenient use resource platform for enterprise staff training and share platform of autonomous learning, or they think the database cannot ascend practical value for enterprise staff's ability. Whatever the reason, obviously enterprise participation enthusiasm is very limited, and its basic reason is that the enterprise has not found more "bonus" in database application training for its employees and potential talent cultivation of universities. These are the natural factors for the difficulty to make the database important link for skill talents and the enterprises. This becomes great barrier for enterprise active sharing of the actual jobs case, resource update, and techniques sharing.

It has become a program teaching resource database system construction face that how to improve the application effect of resource database and realize co-construction of high quality resources sharing, and make the teaching resource not only become an important tool of teaching and learning, but become an important platform [5].

\section{REASON ANALYSIS}

Based on the current resource application situation, the author combines with the concrete practice situation of "higher vocational education numerical control equipment application and maintenance of professional teaching resource database project", makes in-depth research of inefficient application by questionnaire survey, enterprise interviewing, and tracking investigation. The results are summarized as follows:

A. Database access application channel is too single, limited to traditional web access form. Most of the teaching resources are listed according to curriculum, and resource type in each course website, and there is no essential difference between the past single course website. The traditional single access pattern is very difficult to get the favor of young users especially, and on the other hand still continues traditional forms of website which cannot provide users with convenient and effective information.

B. Resource browse and download speed are too slow under single server storage access mode, which is not conducive to database widespread popularization and application. At present the country's teaching database websites are most built in the resource center platform of higher education press with limited online traffic carrying capacity. When online number increases at the same time, network "traffic jam" phenomenon often appears, and the access speed will be reduced which may greatly discourage the user's access. The first important element of an attractive network platform in addition to rich resources in content and practice, is convenient to access, therefore, the existing network platform model is insufficient to support national database's wide range application requirements. 
C. Resources construction content cannot reflect enterprise needs. Database content does not match professional post's national vocational qualification requirements, lack of the industry's latest projects and case studies of enterprise production line, lack of latest industry trends, technology trends, advanced equipment and technology updates. Organization of teaching resources is not strict, and resource service object is not clear. Single course construction ignores professional construction as a whole. Teaching resources construction only pays attention to the number, and has not form a set of high quality teaching material with inner logic around a knowledge point.

D. The database construction only attaches importance to "university-enterprise construction", and despises "university-enterprise sharing". In fact, the latter has huge influence on the former. The enterprise can only get real practical value from sharing, and in turn, be more actively in construction, and get more good resources to build a database, otherwise the enthusiasm of enterprises must be limited. Therefore database construction must make the enterprise really get valuable "bonus" from "application" to further promote and share. For enterprise, the biggest bonus is to let the database be important platform of enterprise staff training and ability improvement. Once the enterprise can really apply this database platform, it will inevitably be more willing to put more advanced, real cases in the database and the participate enthusiasm of co-construction and sharing will be greatly improved. College students' mastery of the knowledge by contact with the latest and the most practical technology is a huge "bonus", in turn, for professional and technical personnel for enterprises in the future. This will obviously be a very good virtuous cycle. At the same time, it has a good role in promoting teacher's teaching in class and university-enterprise's scientific research cooperation. Students, teachers, and enterprises should be a tripartite structure which takes database as the hub with mutually beneficial interaction and mutual promotion, which is shown in Figure 1. Only pay attention to the needs of the enterprise, and attach importance to the sharing between colleges and enterprises, can we promote the co-construction and sharing between the two parties and form good cooperation community?

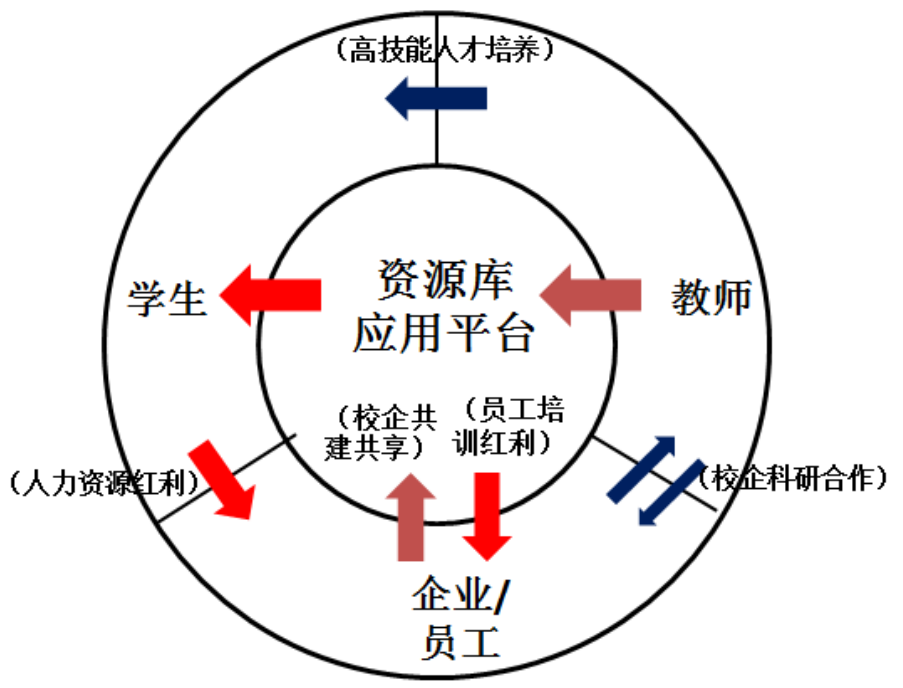

Figure 1 Student - teacher - enterprise tripartite structure model

E. Database's late maintenance and updating resources become a mere formality. Database construction is completed after acceptance, and the late application database, maintenance, resource update cannot get attention, which leads to some database content resources can't keep up with new technology requirements and the resource data has become a decoration.

\section{SUGGESTIONS AND SOLUTIONS}

Database construction's ultimate goal should be fully applied in domestic universities and related industry enterprises, and be an integrated application platform with three-dimensional integration of students' autonomous learning platform, teachers organize teaching platform, and enterprise staff training and learning improvement. Therefore, we must highlight database platform application in position to promote, attach great importance to the application of actual effect, and make the 
teachers and students in colleges and universities, enterprise personnel gain more from database application "bonus". To this end, the author thinks that the construction and application of database should consider the following improvements:

A. Resource sharing platform should adapt to the development trend of mobile Internet, offer a variety of convenient access forms, and strengthen the interactive application of teaching database content. With high-speed development of mobile Internet, people use mobile phones, IPad etc. to surf the Internet more and more, so resource platform should take the initiative to meet the needs of users, in addition to the traditional web access, develop more handy access to mobile phone apps, establish WeChat public accounts, release the latest information in time, and let the teachers and students in colleges and universities, corporate users easily access query database content anytime and anywhere, which is very important to the resource platform application. At the same time, there is a need to increase the interactivity when learners using the database, design the database platform with a more humanized idea, and make resource platform better become learners' personalized service center of autonomous learning.

B. Use big data and cloud storage concept to design resource sharing platform network. Content and speed are two key applications. With good content, and no quick and easy access speed, database platform also fails to attract users. To create good network environment for database platform operation, we must introduce advanced technology support. The existing single server storage access pattern of the database platform has a lot of defects on the access speed, which greatly influences the users use enthusiasm of the database. Therefore we should adopt more layouts, cloud storage thought to design network resource sharing platform to maximize access and resource download speed.

C. Resource planning and design should fully consider the enterprise's practical application demand; make the enterprise make full use of the resource platform as important platform for personnel training and skill accumulation. When design resource planning, absorb as much as possible of the typical enterprise personnel to involve in planning, make the content of the database and case as much as possible close to enterprise actual job content. And experts design case and curriculum with reference of enterprise staff training to make the resource's content close to the actual position. This is very good for students and staff, and can arouse the enthusiasm of enterprises involvement in resource construction, and provide better protection for future resources update, case update, and technology upgrade.

D. Database site design should reflect human resources, and resource search should be convenient, intuitive with clear navigation, easy to download, and easy to browse. Existing database sites in same profession are independent between each course, so the correlation of knowledge connection is not reflected. "Fragmented" phenomenon is outstanding, and the resources list is in chaos with blur navigation. This is bad for the establishment of autonomous learning solutions to users. Therefore, when designing website, fully study the characteristics of the user object, clear navigation, and provide as much as possible matching, clear plan of study for different users.

E. Resources form as far as possible reflects the characteristics of "specific, concrete, and detailed". Namely for specific knowledge and specific problems, give a practical solution, and present as far as possible in the form of a "micro class" essence. Big and long knowledge pile cannot adapt to learners, especially the characteristics of higher vocational students, and short and fine form "micro class" is helpful for learners' learning, and adapts to the characteristics of autonomous learning. So Internet database content should play the characteristics of micro class as far as possible.

F. Resources construction content should be more open. First of all, the construction of the database should be a process of gradually improvement, both in content and technology, information must follow the industry development, and guarantee continuous updates; Secondly, in the development of content resources, make full use of the resources of industry enterprises, introduce industry enterprise standard, and make the course content fully reflect the needs of the enterprises; Third, in database content range degree, not only pay attention to the sharing of advanced domestic colleges and universities' excellent construction achievements, but pay attention to absorb the advanced 
experience of the construction of the teaching resources in foreign famous remote education institutions, and complement each other. Finally, the design of resource's content should be inclusive in a wide range, not only reflect the domestic mutual construction requirements, but keep with characteristic of original creation and teaching information into the database, reflect the original creation, features of teaching results and practice image, and strongly support database's demonstration leading role in higher vocational education.

\section{CONCLUSION}

In general, to cultivate high skill talents to meet the demand of society and enterprise, higher vocational colleges must reform the traditional course centered curriculum resources, take professional demand as the guide, and introduce the principle of work-integrated learning of working process, project teaching, and university-enterprise combination. Carry on the platform construction with learning field curriculum as the basic unit. According to career development stage, gradually progress to organize the courses. At the same time, in order to fully reflect enterprise service function of course, set three sub modules under each course module which consist of curriculum resources, the development of professional skills and professional quality, to fully ensure professional resource platform's full play in training process of society and enterprise needed talents.

The national higher vocational teaching resource database construction gains painstaking effort of thousands of domestic vocational colleges and enterprises, and is a major initiative for China's deepening teaching reform to improve the quality of high-skilled talents cultivation. We need to promote the application of the database to make it really become the important platform of training talents to serve the society. In this paper presents current database application situation, puts forward strategies and suggestions for database applications, and provides the reference direction for the promotion and application of the database and subsequent database construction.

\section{ACKNOWLEDGEMENTS}

[Fund project] Specific improvement scheme combined with the practice and the suggestion project (2012-2-4); Guangdong Education Department higher vocational education teaching reform project ---- numerical control equipment application and maintenance of professional quality course resource construction (201401221);

\section{REFERENCES}

[1] The Ministry of Education, Vocational education and adult education department. Vocational education professional teaching resource database construction guide [R]. 2014-03-13.

[2] Zhou Danong. College-enterprise collaboration platforms: the exploration and practice of cultivation of digital design and manufacture skilled personnel [J]. Journal of Vocational and Technical Education in China. 2015 (17) : 101-107

[3] Li Liping. The construction of the database in higher vocational education teaching reform thinking[J]. China's Higher Education Research. 2011 (6) : 90-91.

[4] Dai Yong. Sharing model teaching resource construction core problems research in higher vocational colleges [J]. China's Higher Education Research. 2010 (3) : 80-81.

[5] Fan YangZu. Efficiency control mechanism research in teaching database system operation [J], China Education Informatization. 2011 (11) : 7-9 